\title{
Parasitic contamination of fresh vegetables sold at central markets in Khartoum state, Sudan
}

\author{
Mona Ali Mohamed ${ }^{1,2^{*}}$, Emmanuel Edwar Siddig ${ }^{3}$, Arwa Hassan Elaagip ${ }^{1}$, Ali Mahmoud Mohammed Edris ${ }^{3}$ \\ and Awad Ahmed Nasr ${ }^{1}$
}

\begin{abstract}
Background: Fresh vegetables are considered as vital nutrients of a healthy diet as they supply the body with essential supplements. The consumption of raw vegetables is the main way for transmission of intestinal parasitic organisms. This study was aimed at detecting the parasitic contamination in fresh vegetables sold in two central open-aired markets in Khartoum state, Sudan.
\end{abstract}

Methods: In this prospective cross-sectional study, a total of 260 fresh vegetable samples and 50 water samples used to sprinkle vegetable(s) were collected from two central open-aired markets (namely; Elshaabi and Central markets) during November 2011 to May 2012. The samples were microscopically examined for detection of parasitic life forms using standardized parasitological techniques for protozoans and helminthes worms.

Results: Of the 260 fresh vegetable samples, 35 (13.5\%) were microscopically positive for intestinal parasites whereas $7 / 50$ (14\%) of water samples used to sprinkle vegetable(s) were found positives. Remarkably, high level of contamination in fresh vegetable samples was recorded in lettuce (Lactuca sativa) $36.4 \%$ (4/11) while cayenne pepper (Capsicum annuum) and cucumber (Cucumis sativus) were not contaminated. The identified protozoans and helminthes were Entamoeba histolytica/dispar, Entamoeba coli, Giardia lamblia, Ascaris lumbricoides, Strongyloides stercoralis, T. trichiura and hookworms. The most predominant parasite encountered was E. histolytica/dispar (42.9\%) whereas both T. trichiura and A. lumbricoides (2.9\%) were the least detected parasites. None of the fresh vegetables had single parasitic contamination. The highest percentages found in water samples used to sprinkle vegetable(s) was for Strongyloides larvae $60 \%$ (3/5). It is worth-mentioned that the rate of contamination in Elshaabi market was higher compared with Central market. However, there was no significant correlation between the type of vegetables and existence of parasites in both markets and a high significant relationship was observed between the type of parasite and total prevalence in fresh vegetables $(p=0.000)$.

Conclusion: The study has identified a moderate rate of fresh vegetables contaminated with protozoan and helminthes. Contaminated fresh vegetables in central markets of Khartoum state may play a significant role in transmission of intestinal parasitic infections to humans, and the water used by greengrocers to sprinkle vegetable(s) can be implicated in vegetable contamination.

Keywords: Parasitic contamination, Fresh vegetables, Intestinal parasites, Khartoum, Sudan

\footnotetext{
*Correspondence: mama-lab12@hotmail.com

1 Department of Parasitology and Medical Entomology, Faculty of Medical

Laboratory Sciences, University of Khartoum, Khartoum, Sudan

Full list of author information is available at the end of the article
} 


\section{Background}

Vegetables are essential for a healthy human body, as they form a major component of human diet in every family [1]. Consuming fresh vegetables usually reduces the risk of stroke, cardiovascular diseases, and protects against certain types of cancers [2,3]. Moreover, vegetables are vital sources of energy that are depended upon by all levels of human as food supplements or nutrients [4]. They substantially improve food quality as rich sources of water, vitamin $\mathrm{C}$, carotene, mineral elements such as iron, and vitamins including thiamine (vitamin B12), niacin and riboflavin [5-7].

In many countries, vegetables are eaten raw or lightly cooked to preserve flavor, and this practice may favor the likelihood of food-borne parasitic infections $[8,9]$. Vegetables become a potential source of human infections like enteric bacterial, viral and parasitic pathogens by contamination during production, collection, transport, preparation and/or during processing $[2,3,10]$. Additionally, the sources of contamination more often are soil, faeces (human and animal origin), water (irrigation, cleaning) $[3,5,11]$. More still, contamination may also occurs when fresh vegetables are rinsed and sprinkling with contaminated water $[3,12]$.

Recently, it has been reported that there is an increasing number of cases of food-borne illness mainly linked to eating fresh vegetables $[2,9,12]$. Parasitic infections lead to about 300 million severely illnesses with approximately 200,000 deaths occurring in developing countries [7]. Tremendous outbreaks of intestinal parasitic infections that were associated with raw vegetables have been reported from developed and developing countries as well $[5,10]$, these probably were due to poor sanitation and inadequate personal hygiene [13]. Several surveys have been done in different parts of the world such as in Syria [2]; Ghana [7]; India [9]; Pakistan [10]; Iran [5, 6, 12]; Nigeria [1, 3, 4, 14]; Vietnam [15, 16]; Ethiopia [11, 13, 17]; Egypt $[8,18]$ indicated that the vegetables can be a major source for transmitting protozoan cysts (E. histolytica; Giardia lamblia; E. coli; Balantidium coli), oocysts (Isospora belli; Cryptosporidium spp.) and helminthes' eggs and larvae (Strongyloides stercoralis; T. trichiura; Enterobius vermicularis; Fasciola hepatica; A. lumbricoides; Toxocara spp.; Hymenolepis nana; Hymenolepis diminuta; Taenia spp.).

Notwithstanding, eating of raw vegetables and salads is the most common practice among Sudanese societies. Accordingly, the risk of intestinal parasitic infections increases especially when they are insufficiently washed. In that vein, the present study endeavors to detect parasites in fresh vegetables, because it is not enough to depend merely on the chemotherapeutic intervention of identified cases, but efforts needed to reduce and eliminate the potential sources of infection in Sudanese local populations. All of these have urged the undertaking of this study to investigate the level of parasitological contamination of fresh vegetables sold in central openaired markets in Khartoum state, Sudan.

\section{Methods \\ Study area}

A prospective cross-sectional study was conducted in Khartoum state during November 2011 to May 2012. Fresh vegetable samples were collected randomly from two central open-aired markets; Elshaabi market in Omdurman town and Central market in Khartoum town (Fig. 1). These markets were considered central as majority of fresh vegetables as well as fruits were brought from different farms and agricultural schemes in different parts of Sudan and sold in these markets. These vegetables were pre-washed before placed on shelves of markets.

\section{Sample collection and processing}

A total of 260 fresh vegetable samples including 11 different types that are frequently consumed were picked randomly after getting consent to participate in the study. Vegetables were taken from greengrocers in the central open-aired markets (130 samples/market). In each market, samples were collected under normal purchase conditions from three randomly selected sellers. Samples were collected from the upper, middle and lower shelves of each seller. Likewise, fifty water samples used to sprinkle vegetable(s) were collected ( 25 samples/market).

The fresh vegetable samples collected in this study were tomatoes (Solanum lycopersicum), lettuce (Lactuca sativa), carrots (Daucus carota), cucumber (Cucumis sativus), Armenian cucumber (Cucumis meloflexuosus), radish (Raphanus sativus), watercress (Nasturtium officinale), green onion (Allium cepa), beet (Beta vulgaris), cayenne pepper (Capsicum annuum), and green pepper (Capsicum sp.). Fresh vegetables were collected into sterile, labeled polythene bags and transported immediately to the laboratory of Parasitology and Medical Entomology at Faculty of Medical Laboratory Sciences, University of Khartoum for parasitic examination. The label was referred to sample type, date of collection and name of market. Water samples used to sprinkle vegetable(s) were collected in clean universal containers $(60 \mathrm{ml})$.

The fresh vegetable samples were washed in $10 \%$ formal saline $(150 \mathrm{ml})$ for detaching the parasitic stages (ova, larvae, cysts, and oocysts) of helminthes and protozoan parasites commonly assumed to be associated with vegetable contamination. The washing saline and water samples used to sprinkle vegetable(s) were transferred to $12 \mathrm{ml}$ conical glass centrifuge tubes. For concentrating the parasitic stages, the tubes were centrifuged at 

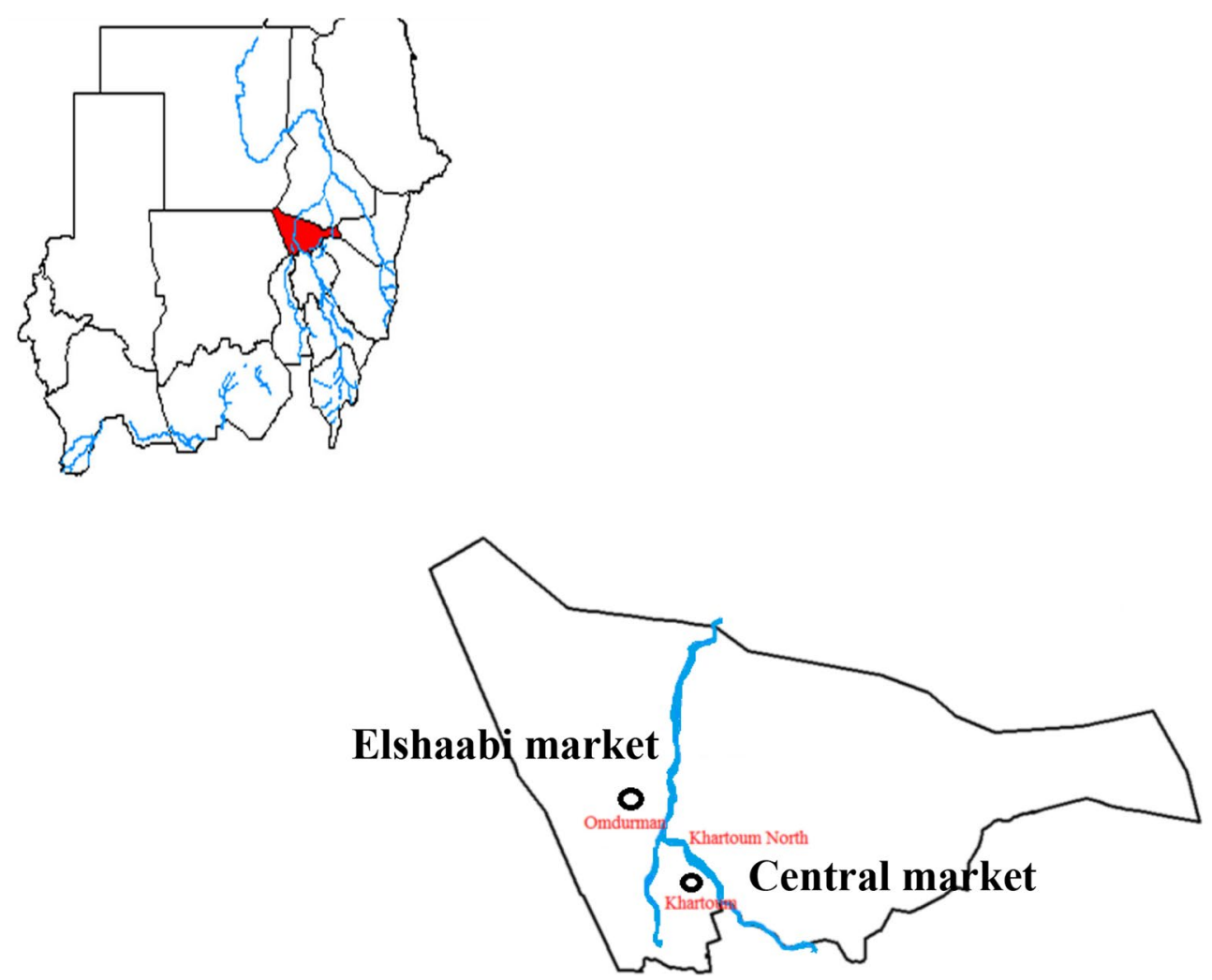

Fig. 1 Map shows the study area (Elshaabi market in Omdurman and Central market in Khartoum)

$3000 \mathrm{rpm}$ for $5 \mathrm{~min}$ [1]. After centrifugation, the supernatant was carefully siphoned off without shaking. Then the sediment was agitated gently by hand for redistributing the parasitic stages. Finally, the sediment was examined under light microscope using $10 \times$ and $40 \times$ objectives. Three slides were prepared from each sample to increase the chance of parasite detection. Then an iodine stained smear was prepared by adding a small drop of Lugol's iodine solution prior to coverslipping to a slide similarly prepared for the unstained smear. The eggs/cysts were identified based on morphological details as described by Soulsby [19].

\section{Statistical analysis}

Data analysis was done using SPSS 20.0. The Chi square test and analysis of variance ANOVA were used to find out the association between the acquisition of parasitic infection in fresh vegetables and type of parasites and to check the significance between the type of contaminated parasite and type of vegetable and water samples used to sprinkle vegetable(s). The $\mathrm{p}$ value $<0.005$ was considered as significant.

\section{Results}

A total of 260 fresh vegetable samples and 50 water samples used to sprinkle vegetable(s) were examined for the presence of parasite contamination. Helminthic eggs and protozoan cysts were detected in $13.5 \%(35 / 260)$ of fresh vegetables examined and in $14 \%(7 / 50)$ of water samples used to sprinkle vegetable(s) (Table 1). Interestingly, the most detected parasites in the vegetable samples in both markets were E. histolytica/dispar (42.9\%), G. lamblia (22.9\%), E. coli (14.3\%), Strongyloides stercoralis $(8.6 \%)$, hookworm's eggs (5.7 \%), T. trichiura and A. lumbricoides (2.9 \%) for each (Table 2) (Fig. 2a, b). The most contaminated vegetables were lettuce (36.4\%) followed by watercress (30.4\%) and no parasite was detected in both of cucumber and cayenne pepper $(0 \%)$ (Table 1).

The predominant parasites found in water samples used to sprinkle vegetable(s) were Strongyloides stercoralis (42.9\%), G. lamblia, A. lumbricoides (28.6\%) for each, and finally $E$. coli (14.3\%) (Table 2).

Furthermore, the rate of contamination among fresh vegetables examined in Elshaabi market was much higher $(13.8 \%)$ compared with Central market (10.8 \%) (Table 1). Similarly, in water samples used to sprinkle vegetable(s) in Elshaabi market was high (15.4\%) compared with Central market (11.6\%) (Table 1).

It is worth mentioning that among all examined fresh vegetable samples none of them had single parasitic 
Table 1 Distribution of intestinal parasitic contamination in different fresh vegetables among the two markets

\begin{tabular}{|c|c|c|c|c|c|c|}
\hline \multirow[t]{2}{*}{ Vegetable type } & \multicolumn{2}{|c|}{ No. of examined samples } & \multicolumn{2}{|l|}{ Central market } & \multicolumn{2}{|l|}{ Elshaabi market } \\
\hline & Examined & Positive (\%) & No. of examined & No. of positives (\%) & No. of examined & No. of positives (\%) \\
\hline Tomatoes & 36 & $4(11.1)$ & 21 & $2(9.5)$ & 15 & $2(13.3)$ \\
\hline Cucumber & 12 & $0(0)$ & 4 & $0(0)$ & 8 & $0(0)$ \\
\hline Armenian cucumber & 16 & $3(18.8)$ & 5 & $0(0)$ & 11 & $3(27.3)$ \\
\hline Green pepper & 25 & $2(8)$ & 14 & $2(14.3)$ & 11 & $0(0)$ \\
\hline Cayenne pepper & 7 & $0(0)$ & 3 & $0(0)$ & 4 & $0(0)$ \\
\hline Radish & 24 & $2(8.3)$ & 16 & $2(12.5)$ & 9 & $0(0)$ \\
\hline Beet & 19 & $3(15.8)$ & 11 & $1(9.1)$ & 8 & $2(25)$ \\
\hline Watercress & 23 & 7 (30.4) & 14 & $5(35.7)$ & 9 & $2(22.2)$ \\
\hline Lettuce & 11 & $4(36.4)$ & 5 & $1(20)$ & 6 & $3(50)$ \\
\hline Green onion & 36 & $5(13.9)$ & 18 & $2(11.1)$ & 18 & $3(16.7)$ \\
\hline Carrot & 50 & $5(10)$ & 19 & $0(0)$ & 31 & $5(16.1)$ \\
\hline Total & 260 & $35(13.5)$ & 130 & $15(11.6)$ & 130 & $20(15.4)$ \\
\hline Vegetables' refreshing water & 50 & $7(14)$ & 25 & $3(12)$ & 25 & $4(16)$ \\
\hline Total & 50 & $7(14)$ & 25 & $3(12)$ & 25 & $4(16)$ \\
\hline
\end{tabular}

contamination (Table 3) and there was multiple contamination (G. lamblia and A. lumbricoides) recorded in single water sample used to sprinkle vegetable(s) collected from Central market (Table 2).

However, there was no significant correlation between the type of vegetable and existence of parasites in both markets ( $p<0.301)$. Importantly, a significant relationship was observed between the type of parasite and total prevalence in fresh vegetables $(p<0.000)$ in both markets.

In this study larvae and adult nematodes were detected among around 34 samples of fresh vegetables. The largest numbers were detected in green onion and beet, but these stages were excluded because of their characteristic features that differ from that of human pathogens (Fig. 3).

Table 2 Distribution of intestinal parasitic contamination in fresh vegetable samples and vegetables' refreshing water samples among the two markets

\begin{tabular}{lll}
\hline $\begin{array}{l}\text { Detected } \\
\text { organism }\end{array}$ & $\begin{array}{l}\text { Total prevalence } \\
\text { in fresh } \\
\text { vegetables (\%) }\end{array}$ & $\begin{array}{l}\text { Total prevalence } \\
\text { in vegetables' } \\
\text { refreshing water (\%) }\end{array}$ \\
\hline E. spp. cyst & $15(42.9)$ & - \\
G. lamblia cyst & $8(22.9)$ & $2(28.6)$ \\
E. coli cyst & $5(14.3)$ & $1(14.3)$ \\
S. stercoralis ova & $3(8.6)$ & $3(42.9)$ \\
Hookworms egg & $2(5.7)$ & - \\
T. trichiura ova & $1(2.9)$ & - \\
A. lumbricoides ova & $1(2.9)$ & $2(28.6)$ \\
\hline
\end{tabular}

\section{Discussion}

The force of habit of eating raw vegetables plays a critical epidemiological role in transmitting parasitic food-borne diseases [2, 6]. Recovery of parasites from fresh sold vegetables is an indication of the quality of the overall process of cultivation, irrigation and post-harvest handling, and may be helpful in indicating the incidence of intestinal parasites among a local community $[2,3]$.

The present study has shown that 11 fresh vegetables routinely used for human consumption in Khartoum state, Sudan, were contaminated with several parasitic stages. Furthermore, study by Shahonazi and JafariSabet 2010 [20] has pointed out that the poorly washed vegetables are considered to be a major route for transmitting intestinal parasitic infections. Unfortunately, the prevalence rate of contaminated vegetable samples was found to be $13.5 \%$ whereas for water samples used to sprinkle vegetable(s) was found to be $14 \%$ in both markets. Fortunately, comparing this result with other studies, it was lower than many studies done in Syria [2], Iran $[5,6,12]$, Pakistan [10], Ethiopia [11, 13, 17], Egypt [8, 18], Nigeria [1, 3, 4] and Vietnam [16]. Additionally, it is much higher than a study has been conducted in Nigeria [14] with $11.0 \%$ prevalence. Probably, this variation in contaminations may be attributed to geographical location, type and number of samples examined, methods used for detection, different laboratory techniques used, type of water used for irrigation, post harvesting handling methods of such vegetables and even the type of water used to wash vegetables can play an instrumental role in the epidemiology of transmission of parasitic diseases. 


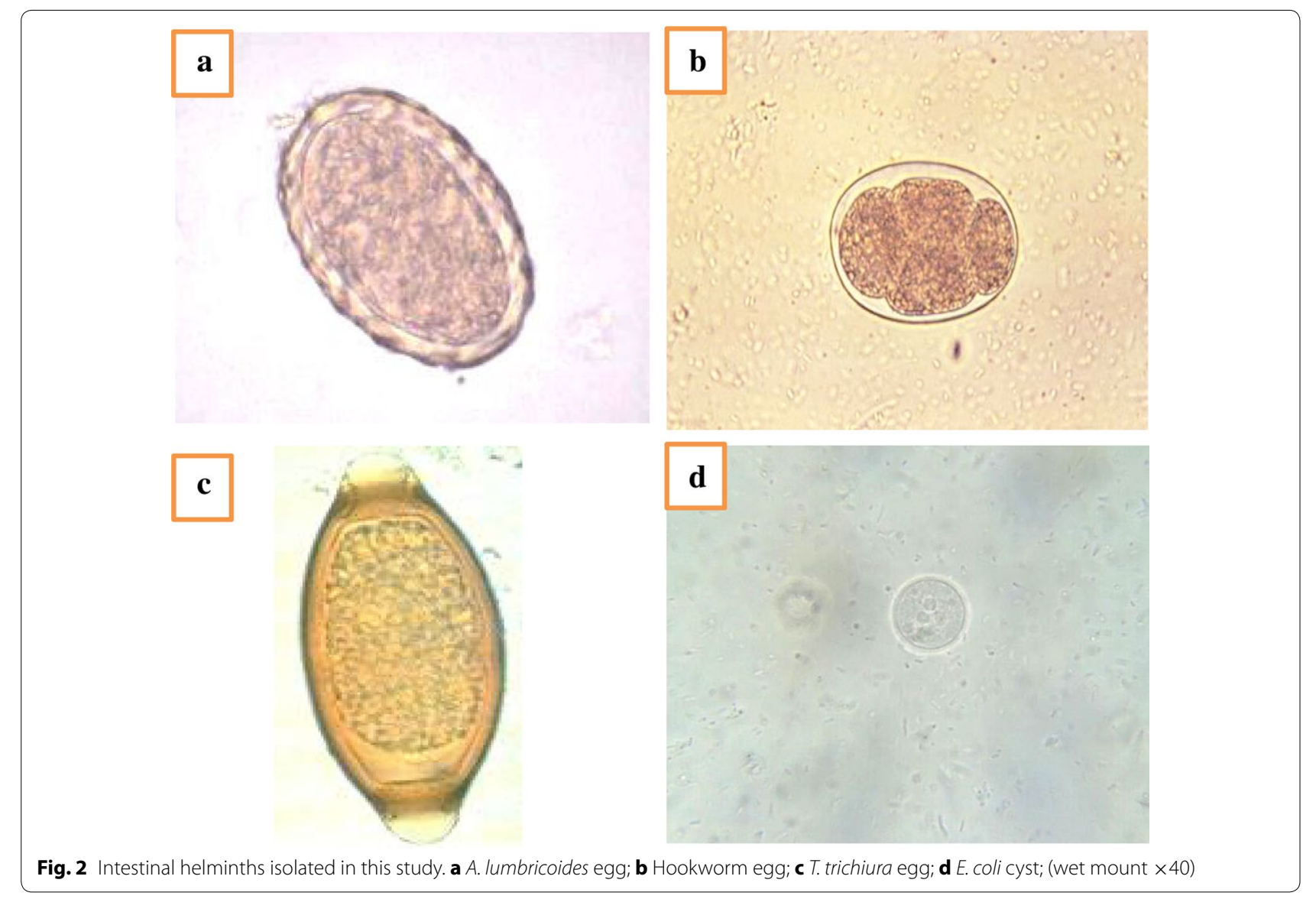

Table 3 Distribution of intestinal parasites in relation to the type of fresh vegetable samples collected from both markets

\begin{tabular}{|c|c|c|c|c|c|c|c|c|}
\hline Vegetables & E. coli cyst & E. spp. cyst & G. lamblia cyst & $\begin{array}{l}\text { A. lumbricoides } \\
\text { ova }\end{array}$ & S. stercoralis ova & Hookworms egg & T. trichiura ova & Total \\
\hline Tomatoes & 1 & 1 & 1 & 1 & 0 & 0 & 0 & $4 / 36$ \\
\hline Cucumber & 0 & 0 & 0 & 0 & 0 & 0 & 0 & $0 / 12$ \\
\hline $\begin{array}{l}\text { Armenian } \\
\text { cucumber }\end{array}$ & 0 & 2 & 0 & 0 & 0 & 0 & 1 & $3 / 16$ \\
\hline Green pepper & 0 & 1 & 1 & 0 & 0 & 0 & 0 & $2 / 25$ \\
\hline Cayenne pepper & 0 & 0 & 0 & 0 & 0 & 0 & 0 & $0 / 7$ \\
\hline Radish & 1 & 0 & 1 & 0 & 0 & 0 & 0 & $2 / 24$ \\
\hline Beet & 1 & 1 & 0 & 0 & 0 & 1 & 0 & $3 / 19$ \\
\hline Watercress & 1 & 1 & 2 & 0 & 2 & 1 & 0 & $7 / 23$ \\
\hline Lettuce & 1 & 2 & 1 & 0 & 0 & 0 & 0 & $4 / 11$ \\
\hline Green onion & 0 & 4 & 1 & 0 & 0 & 0 & 0 & $5 / 36$ \\
\hline Carrot & 0 & 3 & 1 & 0 & 1 & 0 & 0 & $5 / 50$ \\
\hline Total & 5 & 15 & 8 & 1 & 3 & 2 & 1 & $35 / 260$ \\
\hline
\end{tabular}

The present study was in assent with many exhaustive studies $[2,9,10,12,18]$ in that the lettuce had the highest prevalence of contamination, and this may be ascribed to it is leaves which are capable of harboring parasites in-between and in addition to its uneven surfaces on which parasites are attached more easily than other vegetables with smooth surfaces i.e. cucumber, cayenne pepper, green pepper and tomatoes and this 


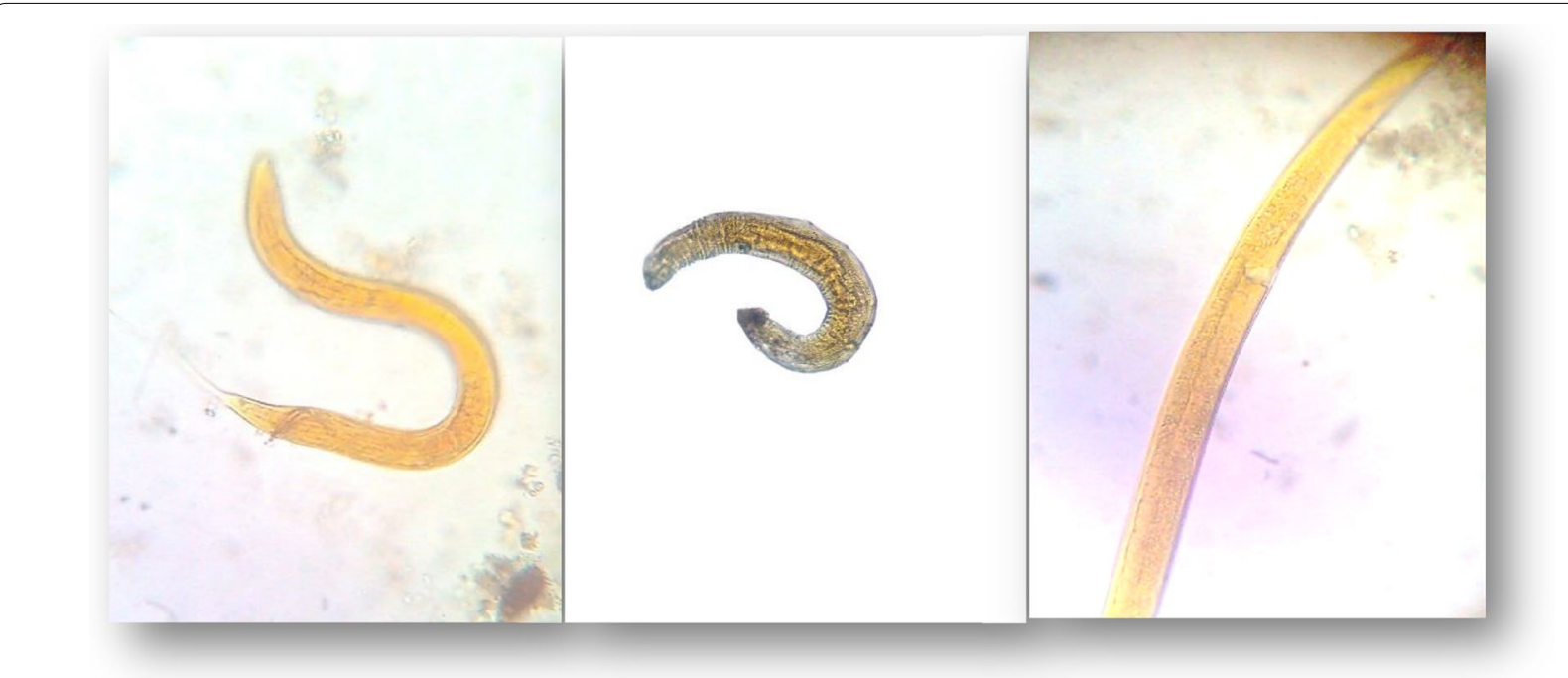

Fig. 3 Different non-pathogenic nematode larvae and adults ( $\times 40)$

observation in accordance with finding by Damen (2007) [21].

It is well evident that the most detected parasite was E. histolytica/dispar in fresh vegetable samples, and this result in accordance with study conducted by Benti and Gemechu (2014) [17]. Notwithstanding, cayenne pepper and cucumber were found free of parasites and this in accord with ul-Hag et al. (2014) [10] who found that cayenne pepper was less contaminated by parasitic infections in Lahore, Pakistan.

Post-harvest faecal contamination which may occurs during handling and transport usually occurs through splashing the vegetables with contaminated water from dirty containers or unhygienic handling in order to keep them fresh. This is supported by this study in which there was $14 \%$ of 50 water samples used to sprinkle vegetable(s) were found to harbor parasitic stages. The greengrocers of the markets buy water for washing and freshening vegetables. The water is brought from outside the market in containers carried by cart because the markets lack healthy piped water form reservoir. Most of the water samples used to sprinkle vegetable(s) were dirty due to dust and vegetable debris.

All isolated fresh vegetable samples and one sample of water used to sprinkle vegetable(s) had more than one species of parasite per sample, and this reflects the magnitude of a single faecal contamination of vegetables which may results in several parasitic infections [14].

\section{Conclusions}

In conclusion, few types of fresh vegetables in Khartoum area were moderately contaminated by intestinal parasites than other areas. This is suggested that humans are at high risk of getting infections from contaminated fresh vegetables eaten on daily basis. These findings raised concern of public health being at high risk of infection with amoebiasis, G.sis, strongyloidiasis, ascariasis and others. So, adopting control measures that cover guidelines of irrigation water quality, strategies to reduce the risk of disease transmission by food-borne parasites, preventing domestic and wild animals from entering into the plant farms and avoiding to use untreated night soil as fertilizer is highly recommended. Effective and comprehensive prevention and treatment measures should be taken to ensure food safety. Washing procedures before eating raw vegetables regardless of the provider's sanitation should be performed to avoid transmission of intestinal parasites.

\section{Authors' contributions}

MAM and AAN conceived and designed the study; MAM and EES performed the study; MAM, EES, AHE, AME and AE analyzed the data; MAM, EES, AME, $\mathrm{AE}$ and $\mathrm{AHE}$ wrote the manuscript. All authors read and approved the final manuscript.

\section{Author details}

${ }^{1}$ Department of Parasitology and Medical Entomology, Faculty of Medical Laboratory Sciences, University of Khartoum, Khartoum, Sudan. ${ }^{2}$ Nile College, Khartoum, Sudan. ${ }^{3}$ Department of Histopathology and Cytology, Faculty of Medical Laboratory Sciences, University of Khartoum, Khartoum, Sudan.

\section{Acknowledgements}

Thanks are given to the greengrocers enrolled in this study and to Dr. Abdallah M. Samy for statistical advice in data analysis.

\section{Competing interests}

The authors declare that they have no competing interests.

Received: 17 May 2015 Accepted: 3 March 2016

Published online: 11 March 2016 


\section{References}

1. Idahosa OT. Parasitic contamination of fresh vegetables sold in Jos markets. Global J Med Res. 2011;11(1):21-5.

2. Alhabbal AT. The prevalence of parasitic contamination on common cold vegetables in Alqalamoun Region. Int J Pharm Sci Rev Res. 2015;30(1):94-7.

3. Alade GO, Alade TO, Adewuyi IK. Prevalence of intestinal parasites in vegetables sold in Ilorin, Nigeria. Am Eur J Agric Environ Sci. 2013;13(9):1275-82

4. Simon-Oke IA, Afolabi OJ, Obasola OP. Parasitic contamination of fruits and vegetables sold at Akure Metropolis, Ondo State, Nigeria. Researcher. 2014;6(12):30-5

5. Nazemi S, Raei M, Amiri M, Chaman R. Parasitic contamination of raw vegetables in Shahroud, Semnan. Zahedan J Res Med Sci. 2012;14(8):84-6

6. Ebrahimzadeh A, Jamshidi A, Mohammadi S. The parasitic contamination of raw vegetables consumed in Zahedan, Iran. Health Scope. 2013;1(4):205-9.

7. Duedu K, Yarnie E, Tetteh-Quarcoo P, Attah S, Donkor E, Ayeh-Kumi P. A comparative survey of the prevalence of human parasites found in fresh vegetables sold in supermarkets and open-aired markets in Accra,Ghana. BMC Res Notes. 2014;7:836.

8. Said D. Detection of parasites in commonly consumed raw vegetables. Alex J Med. 2012;48:345-52.

9. Sunil B, Thomas D, Latha C, Shameem H. Assessment of parasitic contamination of raw vegetables in Mannuthy, Kerala state, India. Vet World. 2014;7(4):253-6.

10. Ul-Haq S, Maqbool A, Javed Khan U, Yasmin G, Sultana R. Parasitic contamination of vegetables eaten raw in Lahore, Pakistan. J Zool. 2014;46(5):1303-9.

11. Tomass Z, Kidane D. Parasitological contamination of wastewater irrigated and raw manure fertilized vegetables in Mekelle city and its suburb, Tigray, Ethiopia. CNCS Mekelle Univ. 2012;4(1):77-89.
12. Olyaei A, Hajivandi L. Parasitological contamination of markets and farms in vegetables consumed in southern Iran. Global Veterinaria. 2013;10(3):327-31.

13. Tefera T, Biruksew A, Mekonnen Z, Eshetu T. Parasitic contamination of fruits and vegetables collected from selected local markets of Jimma town, southwest Ethiopia. Int Sch Res Not. 2014;2014:382715. doi:10.1155/2014/382715

14. Shehu M, Amina R. Helminths contaminants of fruits and vegetables sold in rural areas of Zamfara States, Nigeria. J Zool Biosci Res. 2014;1 (1):15-9.

15. Chau H, Thong H, Chao N, Hung P, Hai V, An L, Fujieda A, Ueru T, Akamatsu M. Microbial and parasitic contamination on fresh vegetables sold in traditional markets in Hue city, Vietnam. J Food Nutr Res. 2014;2(12):959-64.

16. Uga S, Hoa N, Noda S, Moji K, Cong L, Aoki Y, Rai S, Fujimaki Y. Parasite egg contamination of vegetables from a suburban market in Hanoi,Vietnam. Nepal Med Coll J. 2009;11(2):75-8.

17. Benti G, Gemechu F. Parasitic contamination on vegetables irrigated with Awash river in selected farms, eastern Showa, Ethiopia. J Parasitol Vector Biol. 2014;6(7):103-9.

18. Eraky M, Rashed S, Nasr M, El-Hamshary A, El-Ghannam A. Parasitic contamination of commonly consumed fresh leafy vegetables in Benha, Egypt. J Parasitol Res. 2014;2014:613960. doi:10.1155/2014/613960

19. Soulsby E. Helminths, arthropods and protozoa of domesticated animals., English language book society.London: Baillere Tindall; 1982.

20. Shahnazi M, Jafari-Sabet M. Prevalence of parasitic contamination of raw vegetables in villages of Qazvin Province, Iran. Foodborne Pathog Dis. 2010;7(9):1025-30.

21. Damen J, Banwat E, Egah D, Allanana J. Parasitic contamination of vegetables in Jose, Nigeria. Ann Afr Med. 2007;6:115-8.

\section{Submit your next manuscript to BioMed Central and we will help you at every step:}

- We accept pre-submission inquiries

- Our selector tool helps you to find the most relevant journal

- We provide round the clock customer support

- Convenient online submission

- Thorough peer review

- Inclusion in PubMed and all major indexing services

- Maximum visibility for your research

Submit your manuscript at www.biomedcentral.com/submit

() Biomed Central 